\title{
Microbial lipid production from crude glycerol and hemicellulosic hydrolysate with oleaginous yeasts
}

\author{
Mikolaj Chmielarz, Johanna Blomqvist, Sabine Sampels, Mats Sandgren and Volkmar Passoth * (1)
}

\begin{abstract}
Background: Crude glycerol (CG) and hemicellulose hydrolysate $(\mathrm{HH})$ are low-value side-products of biodiesel transesterification and pulp - and paper industry or lignocellulosic ethanol production, respectively, which can be converted to microbial lipids by oleaginous yeasts. This study aimed to test the ability of oleaginous yeasts to utilise $\mathrm{CG}$ and $\mathrm{HH}$ and mixtures of them as carbon source.

Results: Eleven out of 27 tested strains of oleaginous yeast species were able to grow in plate tests on CG as sole carbon source. Among them, only one ascomycetous strain, belonging to Lipomyces starkeyi, was identified, the other 10 strains were Rhodotorula spec. When yeasts were cultivated in mixed CG/ HH medium, we observed an activation of glycerol conversion in the Rhodotorula strains, but not in L. starkeyi. Two strains-Rhodotorula toruloides CBS 14 and Rhodotorula glutinis CBS 3044 were further tested in controlled fermentations in bioreactors in different mixtures of CG and HH. The highest measured average biomass and lipid concentration were achieved with $R$. toruloides in 10\% $\mathrm{HH}$ medium mixed with $55 \mathrm{~g} / \mathrm{L} \mathrm{CG}-19.4 \mathrm{~g} / \mathrm{L}$ and $10.6 \mathrm{~g} / \mathrm{L}$, respectively, with a lipid yield of $0.25 \mathrm{~g}$ lipids per consumed $g$ of carbon source. Fatty acid composition was similar to other $R$. toruloides strains and comparable to that of vegetable oils.

Conclusions: There were big strain differences in the ability to convert CG to lipids, as only few of the tested strains were able to grow. Lipid production rates and yields showed that mixing GC and HH have a stimulating effect on lipid accumulation in $R$. toruloides and $R$. glutinis resulting in shortened fermentation time to reach maximum lipid concentration, which provides a new perspective on converting these low-value compounds to microbial lipids.
\end{abstract}

Keywords: Oleaginous yeast, Hemicelluloses, Crude glycerol, Lipids, R. torouloides

\section{Background}

There is increased need for recycling of waste products from food, wood industry and agriculture in recent years. Vast quantities of organic residues are a challenge that is being addressed by converting waste and low purity sugars into higher quality products [1].

Crude glycerol (CG) is a side product of biodiesel production, which is released during transesterification of

\footnotetext{
*Correspondence: volkmar.passoth@slu.se
}

Department of Molecular Sciences, Swedish University of Agricultural

Sciences, Uppsala, Sweden vegetable oils. CG is a highly problematic side product; it contains methanol, soap and ash. Industrial application of CG requires extensive purification, making its application quite expensive [2-5]. In recent years there have been developments to utilse glycerol and convert it to useable biomass and for example turn it into microbial fuel cells [6], or to convert glycerol into valuable fatty acids using Yarrowia lipolytica [7]. It was also tested as an additive with other waste substrates to make microbial oil and other valuable products [8-13].

Hemicellulose is, besides of cellulose and lignin, one of the major polymers of the plant cell wall. It is a 
heteropolysaccharide, which composition differs between different groups of plants. Hardwood hemicellulose consists mainly of xylans, while softwood is mainly built of glucomannans. Hemicellulose of lignocellulosic materials of monocoyledons like wheat straw consist of a xylan backbone with side chains of arabinose and glucuronic acid [14, 15]. In pulp and paper industry, hemicellulose is a side product and used for steam generation. However, it is rather inefficient for this application, due to its low heating value $(13.5 \mathrm{MJ} / \mathrm{kg})$ [5]. In lignocellulose-based bioethanol production, separating hemicellulose from the cellulose fraction can be advantageous, since conversion of the pentoses, which are the major sugar monomers of hemicellulose to ethanol is still a challenge [7, 8]. When lignocellulose is thermochemically pretreated by acid hydrolysis, hemicellulose is solubilised and hydrolysed, resulting in the release of monosaccharides [16]. Since the major parts of cellulose and lignin are still in the solid phase, it is easy to separate the hemicellulose hydrolysate from the other components of lignocellulose hydrolysate. Hemicellulose hydrolysates contain, in addition to released sugars, a variety of inhibitors such as furaldehydes, weak organic acids and phenolic compounds [17], and frequently it is necessary to remove those inhibitors or to dilute hemicellulose hydrolysate to enable bioconversion of hemicellulose hydrolysates [13, $18,19]$.

Many oleaginous yeasts, i.e., yeasts that can accumulate more than $20 \%$ of their biomass as lipids, can convert both glycerol as well as sugars and organic acids derived from hemicellulose to oil. This oil has a similar composition as some vegetable oils [20]. Production of vegetable oil can have considerable greenhouse gas potential [21] and thus, replacement of vegetable oil by yeast oil may result in more sustainable biodiesel $[22,23]$ or animal feed production [24]. However, production costs of microbial oil are still too high to be competitive with oil from fossil resources or vegetable oils $[25,26]$. Therefore, it is important to explore the conversion of low-value side products such as lignocellulose hydrolysate, hemicellulose hydrolysate, or crude glycerol to microbial oils. Another approach to improve cost efficiency of microbial lipid production is to identify strains with high productivity when converting the mentioned residual products to lipids and to understand their physiology, to identify targets for strain optimisation [27, 28].

Converting a mixture of CG and $\mathrm{HH}$ to yeast oil may provide a possibility of simultaneously converting these side streams to a high-value products. At the same time, inhibitors present in only one of these side streams might be diluted and thus less inhibitory. It was our aim to get a survey about the diversity of strains when converting $\mathrm{CG}$ and $\mathrm{HH}$ to lipids. We also intended to investigate effects of mixing these two problematic substrates. We tested several of strains belonging to the genera Lipomyces (ascomyceteous oleaginous yeasts) and Rhodotorula (basidiomycetous oleaginous yeasts) for their ability to grow and synthetise lipids on a mixture of CG and $\mathrm{HH}$.

\section{Results \\ Crude glycerol and hemicellulose growth tests}

The ability of 27 yeast strains to utilise CG as sole carbon source and their resistance against inhibitors in CG was tested on solid media. A droplet of undiluted crude glycerol or a filter soaked with CG was placed at the centre of YNB plates inoculated with the tested strains. Out of the 27 tested strains, 11 strains showed visible growth close to the droplet/filter and thus were able to tolerate CG, and to utilise it as carbon source (experiments were performed in duplicates). Those strains were: Rhodotorula glutinis CBS 2203, $R$. glutinis CBS 2889, $R$. glutinis CBS 2890, R. glutinis CBS 3044, R. glutinis CBS 5182, $R$. glutinis CBS 7538, Rhodotorula minuta CBS 8013, Rhodotorula mucolaginosa CFSQE 63, Rhodotorula babjevae CBS 7809, Rhodotorula toruloides CBS 14 and Lipomyces starkeyi CBS 7786. Interestingly, only one ascomycetous strain (L. starkeyi 7786) showed substantial growth on the plates with crude glycerol. These strains were also tested in liquid shake flask cultures with $40 \%$ hemicellulose hydrolysate as sole carbon source, and in cultures with different concentrations of crude glycerol (up to $120 \mathrm{~g} / \mathrm{l}$ ) as sole carbon source. After $96 \mathrm{~h}$ of cultivation almost all red yeast strains grew well in hemicellulose hydrolysate (OD 20-40) and in $120 \mathrm{~g} / \mathrm{L}$ CG (OD > 40). R. minuta CBS 8013 grew slower than other Rhodotorula strains in CG concentrations higher than $60 \mathrm{~g} / \mathrm{L}$. $L$. starkeyi CBS 7786 grew comparatively well in hemicellulose hydrolysate and $30 \mathrm{~g} / \mathrm{L}$ CG medium, but had lower growth compared to the tested red yeast strains in higher concentrations of CG.

\section{Testing of growth in a mixture of crude glycerol and hemicellulose}

To evaluate the effect of mixing CG and $\mathrm{HH}$ in the cultivation media we tested five strains, L. starkeyi CBS 7786, $R$. toruloides CBS 14, $R$. glutinis CBS 3044, $R$. glutinis CBS 2889 and $R$. mucolaginosa CFSQE 63, for their growth on these mixed substrates and compared it to cultivations with either glucose (positive control) or crude glycerol as sole carbon source (Figs. 1-4). The strains were chosen among those that showed good growth on crude glycerol and hemicellulose hydrolysate media. There were varying responses of the strains to the different carbon sources. In the glucose control medium (Control media), $R$. toruloides CBS 14 had the lowest $\mathrm{OD}_{600}$ after $96 \mathrm{~h}$ of cultivation (21), while $R$. 

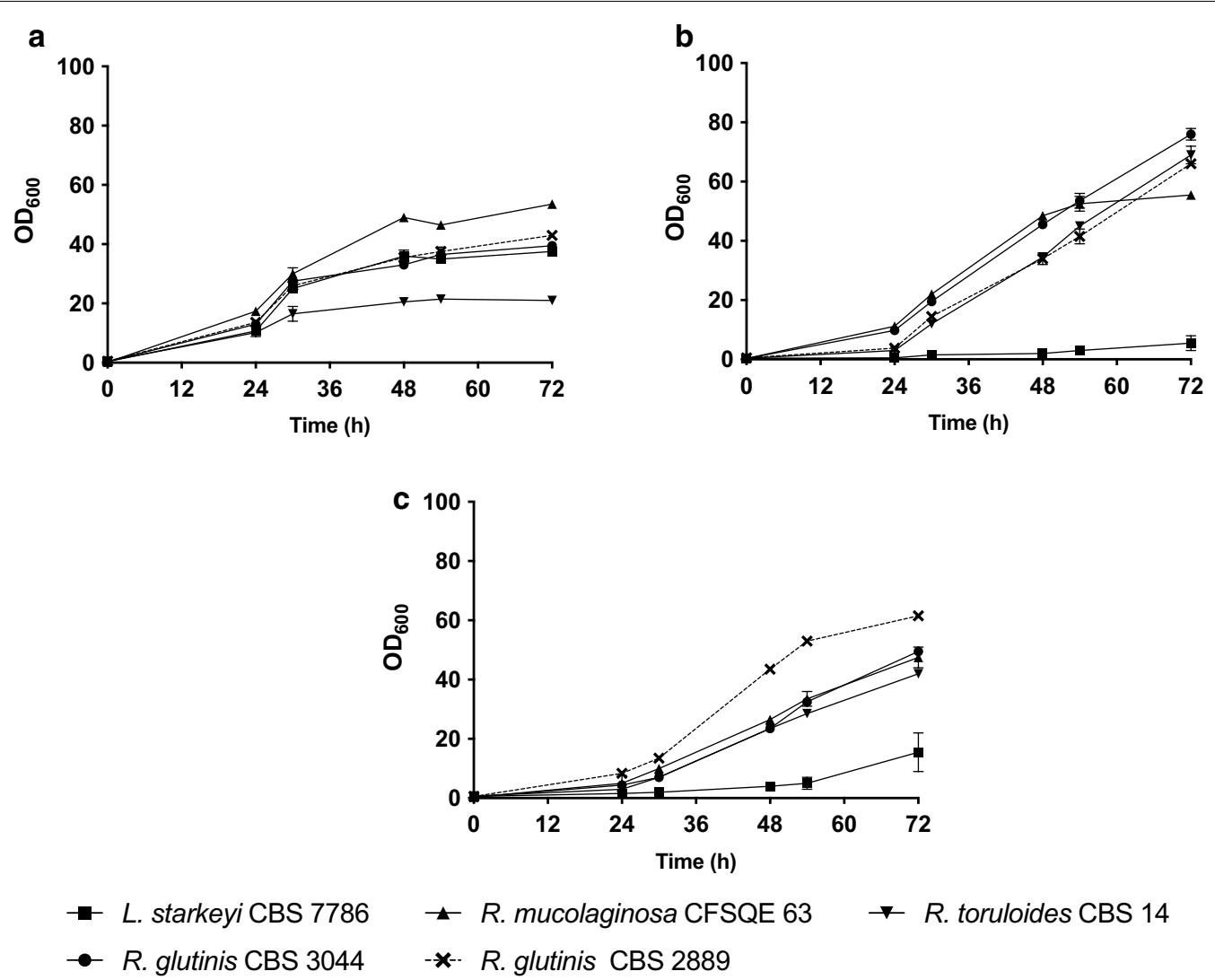

Fig. 1 Growth of five strains tested in different media. a control medium, $\mathbf{b}$ hemicellulose hydrolysate mixed with crude glycerol and $\mathbf{c} c r u d e$ glycerol +YNB media in shake flask cultures. $60 \mathrm{~g} / \mathrm{L}$ Crude Glycerol, and 40\% Hemicellulose hydrolysate. Strains were grown in duplicates

mucolaginosa CFSQE 63 reached an $\mathrm{OD}_{600}$ more than twice as high as $R$. toruloides after $96 \mathrm{~h}$. In mixed media (sHH40CG60 media), results were almost the opposite. $R$. toruloides had the second highest $\mathrm{OD}_{600}$ after $R$. glutinis CBS 3044. Out of the red yeasts, $R$. mucolaginosa CFSQE 63 had the lowest $\mathrm{OD}_{600}$. In media with crude glycerol (sCG60 media) only, R. glutinis CBS 2889 had the highest $\mathrm{OD}_{600}$ and $R$. glutinis CBS 3044 reached the second highest $\mathrm{OD}_{600}$. Interestingly, faster growth was observed for the red yeasts when cultivated using a mixed medium, compared to cultivations using pure CG.

L. starkeyi CBS 7786 showed slow growth on both CG alone and the mixture of CG and HH (Fig. 1). In contrast to the red yeasts, mixing CG with $\mathrm{HH}$ had no stimulating effect but was rather inhibiting the growth. In sHH40CG60 media, from starting glycerol concentration of approximately $50 \mathrm{~g} / \mathrm{L}$, Lipomyces starkeyi CBS 7786 consumed only around $25 \%$ of this, with $38.2 \mathrm{~g} / \mathrm{L}$ glycerol still remaining after $72 \mathrm{~h}$ cultivation (Fig. 2). It was also only able to assimilate a small proportion of xylose, which was consumed by the other tested strains within $30 \mathrm{~h}$.

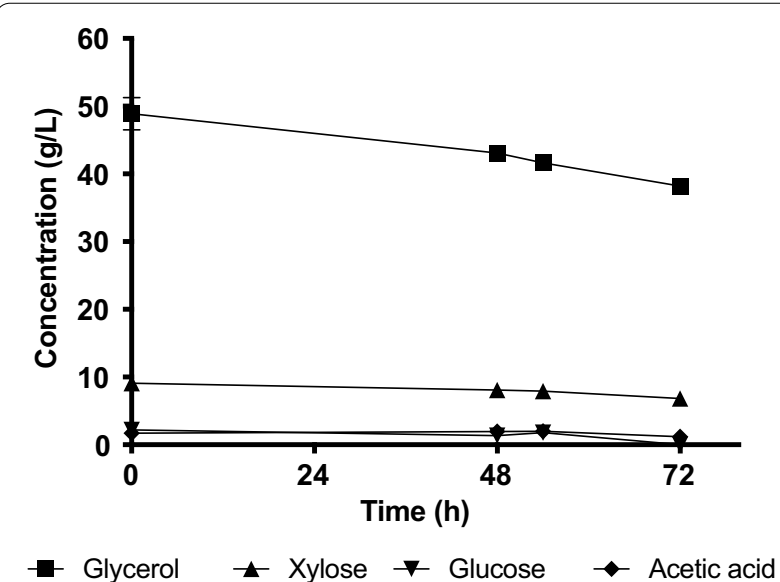

Fig. 2 Carbon source consumption in shake flask cultivation of L. starkeyi CBS 7786 in sHH40CG60 medium. Xylose had a final concentration of $6.8 \mathrm{~g} / \mathrm{L}$; final concentration of glycerol was $38.2 \mathrm{~g} / \mathrm{L}$. The values were obtained from duplicate cultivations

In $R$. toruloides CBS 14 cultivations, the remaining glycerol concentration was $26 \mathrm{~g} / \mathrm{L}$ after $70 \mathrm{~h}$ of cultivation. Xylose consumption started after $30 \mathrm{~h}$ (Fig. 3). $R$. 


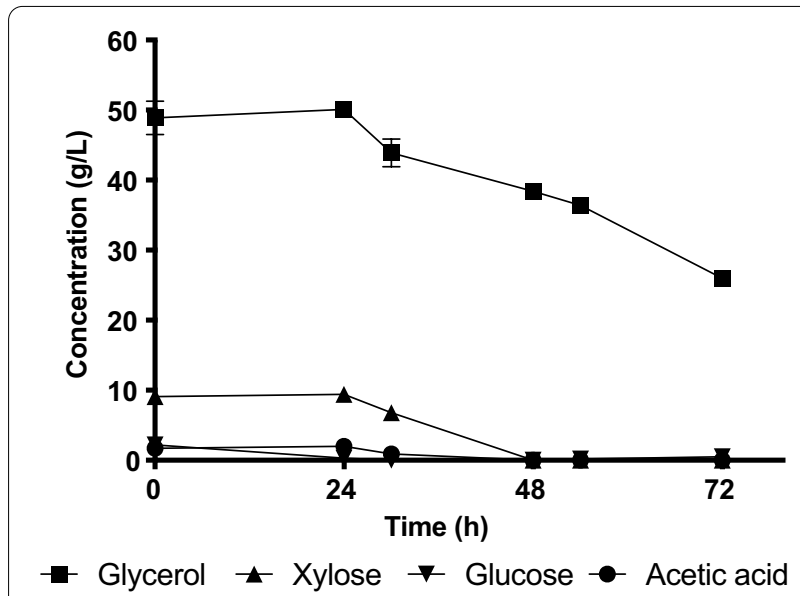

Fig. 3 Carbon source consumption in shake flask culture of $R$. toruloides CBS 14 grown in sHH40CG60. Xylose was consumed after $30 \mathrm{~h}$ of cultivation, glycerol levels were dropping to a final concentration of $26.0 \mathrm{~g} / \mathrm{L}$ after $70 \mathrm{~h}$ of cultivation. Cultivations were grown in duplicates

glutinis CBS 3044 (Fig. 4), also consumed xylose between the 30 and $48-\mathrm{h}$ measurement. The remaining concentration of glycerol was $28.3 \mathrm{~g} / \mathrm{L}$.

For R. mucolaginosa CFSQE 63 and R. glutinis CBS 2889 it turned out to be difficult to measure the concentration of carbon sources in the medium, because during filtration of all samples taken after inoculation, filter membranes rapidly got clogged. Although the supernatants were centrifuged before filtration as described before [19], it was in principle not possible to filter the supernatant and for the little amount of liquid that passed through the filter, results were not reproducible (results not shown). Production of exopolysaccharides has been shown in several strains of Rhodotorula spec. [29-31], and the clogging of the filters may be due to production of those polysaccharides in these two strains. Due to the difficulties in analysing the metabolites in the fermentations, we did not further investigate these strains in this study.

\section{Fermentation in bioreactors}

Two of the investigated strains, $R$. toruloides CBS 14 and R. glutinis CBS 3044, were tested under controlled conditions in $500 \mathrm{ml}$ fermenters for their abilities to utilise crude glycerol and hemicellulose hydrolysate and mixtures of them.

Cultivations were performed in $55 \mathrm{~g} / \mathrm{L}$ of CG (CG55) as sole carbon source for the control and in a mixture of $55 \mathrm{~g} / \mathrm{l}$ glycerol with $10 \% \mathrm{HH}$ (HH10CG55). The C/N ratio of HH10CG55 mixture was 53.6, and CG50 C/N ratio was 48 which are slightly below the reported

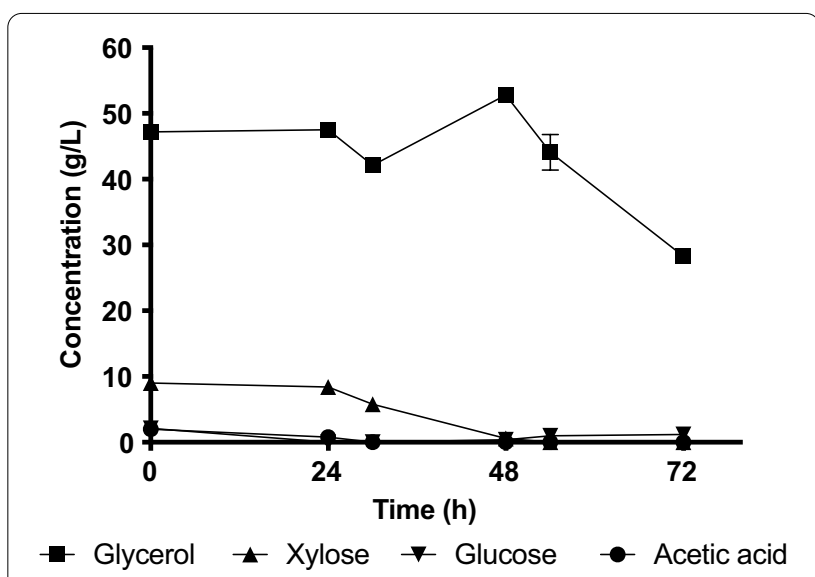

Fig. 4 Carbon source consumption in shake flask culture of $R$. glutinis CBS 3044 grown in sHH40CG60. Xylose was consumed after $30 \mathrm{~h}$ of cultivation, glycerol levels dropped to a final concentration of $28.3 \mathrm{~g} / \mathrm{L}$ after $70 \mathrm{~h}$. Cultivations were grown in duplicates

optimum for lipid production of 60-100 [32]. To obtain an impression on the lipid accumulation kinetics, the intracellular lipid content during fermentation was checked over the whole fermentation time using our recently established FT-NIR-based method for intracellular lipid determination [33].

In the cultivation of $R$. toruloides CBS 14, glycerol was faster consumed in the HHCG mixture, compared to the CG control. After $72 \mathrm{~h}$, more than $75 \%$ of all glycerol was consumed in the mixed medium, and after $96 \mathrm{~h}$ no glycerol was detectable any more. In the control with only CG as carbon source, even after $120 \mathrm{~h}$ of cultivation $4.7 \mathrm{~g} / \mathrm{L}$ glycerol was left in the culture and complete consumption was only found after $144 \mathrm{~h}$. Moreover, the highest cell dry weight $(21.2 \mathrm{~g} / \mathrm{L})$ and lipid concentration $(12.5 \mathrm{~g} / \mathrm{L})$ were reached in the HHGC mixture after $96 \mathrm{~h}$ cultivation (Fig. $5 \mathrm{~b}$ ). In the culture with CG as sole carbon source, the maximum dry weight $(19.1 \mathrm{~g} / \mathrm{L})$ and lipid concentration $(8.81 \mathrm{~g} / \mathrm{L})$ were detected after $140 \mathrm{~h}$ cultivation (Fig. 5a).

Similarly, an activating effect was observed for $R$. glutinis CBS 3044 when cultivated in HHGC compared to CG as sole carbon source (Fig. $5 \mathrm{c}$, d). The glycerol was almost finished after $72 \mathrm{~h}$, while in the control with only CG, more than $40 \%$ of the initial carbon source was present at this time. $R$. glutinis CBS 3044 in CG consumed glycerol slightly faster than $R$ toruloides CBS 14 - all of it was consumed by $120 \mathrm{~h}$. In the culture with CG as sole carbon source, the maximum dry weight $(20.3 \mathrm{~g} / \mathrm{L})$ and lipid concentration $(7.6 \mathrm{~g} / \mathrm{L})$ were detected after $120 \mathrm{~h}$ cultivation (Fig. 5c). Highest lipid concentration $(7.6 \mathrm{~g} / \mathrm{L})$ was reached in the HHGC mixture after $96 \mathrm{~h}$ cultivation (Fig. 5d). The highest cell dry 

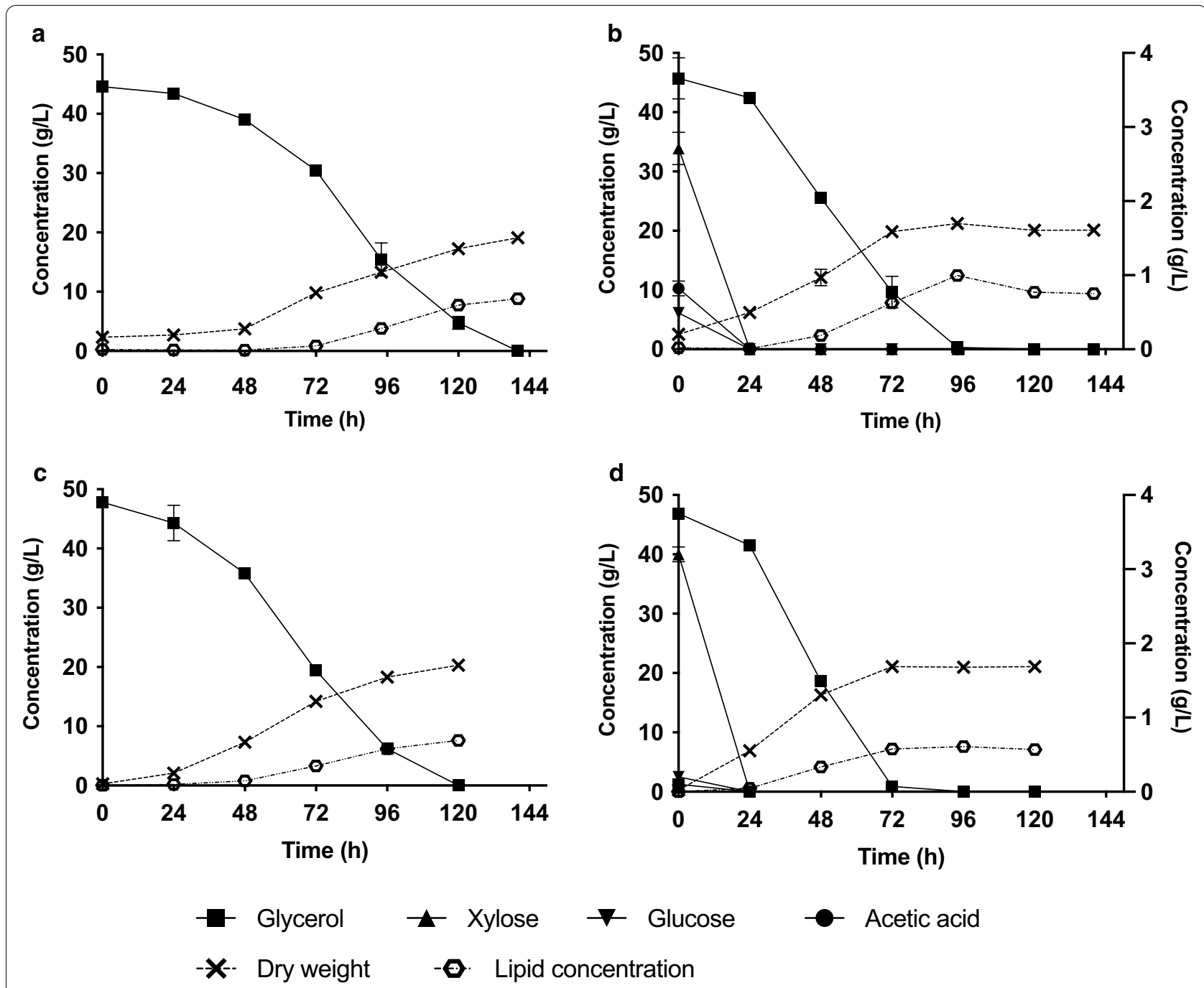

Fig. 5 Dry weight, lipid concentration and carbon source consumption over time in media with CG as sole carbon source (CG55) or mixed carbon source (HH10CG55). a R. toruloides CBS 14 bioreactor cultivation CG55. b R. toruloides CBS 14 bioreactor cultivation in HH10CG55; c R. glutinis CBS 3044 bioreactor cultivation in CG55. d R. glutinis CBS 3044 bioreactor cultivation in HH10CG55; Glucose, xylose and acetic acid are shown on the right $y$ axis. All cultures were done in triplicates

weight $(21.0 \mathrm{~g} / \mathrm{L})$ was achieved after $72 \mathrm{~h}$ and it only changed by $0.1 \mathrm{~g} / \mathrm{L}$ during the next $48 \mathrm{~h}$.

In addition, we analysed the specific lipid production rates in $55 \mathrm{~g} / \mathrm{L}$ CG media (Additional file 1: Fig. S1). The lipid accumulation was highest in both red yeast strains in media containing HH. R. toruloides had similar specific lipid production rates compared to R. glutinis (maximum specific rates of 0.014 vs $0.013 \mathrm{~g} / \mathrm{g} / \mathrm{h}$ ), but growth was delayed by $24 \mathrm{~h}$. According to a fixed effect linear model the hemicellulose hydrolysate additive had a significant impact on $R$. toruloides lipid accumulation $(p<0.001)$ but not on $R$. glutinis $(p=0.0625)$. The volumetric production rates followed the same trend as the specific rates. $R$. toruloides CBS14 in mixed medium had its maximum production rate $(0.23 \mathrm{~g} / \mathrm{L}$ lipid per hour) between 48 and $72 \mathrm{~h}$ of cultivation, in CG medium $R$. toruloides CBS14 had the highest rate $(0.16 \mathrm{~g} / \mathrm{L}$ lipid per hour) between 96 and 120 h. R. glutinis CBS 3044 in mixed medium had its maximum production rate $(0.15 \mathrm{~g} / \mathrm{L}$ lipid per hour $)$ between 24 and $48 \mathrm{~h}$ of cultivation, in CG medium $R$. glutinis CBS 3044 had the highest rate $(0.12 \mathrm{~g} / \mathrm{L}$ lipid per hour) between 72 and $96 \mathrm{~h}$.

These results confirmed under controlled conditions the activating effect of mixing $\mathrm{HH}$ and CG, which we already observed for red yeasts in shake flasks. To further verify this effect, we performed a variety of further controlled fermentations with varying concentrations of CG and HH (Additional file 2: Fig. 2 and Additional file 3: 
Fig. 3). For all tested concentrations (with a $\mathrm{C} / \mathrm{N}$ ratio from 38.3 to 72 ) we found a more rapid glycerol consumption and lipid formation in cultures with a mixed carbon source.

Lipid content, concentration, yield and biomass at the end of fermentation times are presented in Table 1 . In most cases, the final lipid yields per g consumed carbon source were not significantly different between the cultivations with mixed carbon source and CG alone, the major effect was due to more rapid initial glycerol consumption. The highest lipid content was measured in $R$. toruloides CBS 14 grown in HH40CG60 medium (C/N ratio 72.2 ), which was probably due to the higher concentration of carbon source and higher $\mathrm{C} / \mathrm{N}$ ratio. In addition, a comparatively high lipid yield ( 0.23 g lipids per g consumed carbon source) was observed. However, in this cultivation, not all glycerol was consumed and it turned out that the glycerol consumption rate decreased towards the end of the culture (Additional file 3: Fig. 3). In the cultivation with HH10CG55, all carbon source was consumed and the yield was even higher (0.25). The lipid yields of $R$. glutinis CBS 3044 were slightly lower compared to $R$. toruloides CBS 14 .

\section{Fatty acid analysis}

The average fatty acid composition for $R$. toruloides CBS 14 is presented in Table 2 . In all cases, there were four dominant fatty acids; oleic acid, palmitic acid, linoleic acid and stearic acid. Oleic acid (C18:1) was the most common fatty acid with the highest proportion of $46.0 \%$
Table 2 Average fatty acid composition of $R$. toruloides CBS 14 $(n=2)$ in different media (percent (\%) of total identified \pm mean absolute deviation)

\begin{tabular}{lrrrr}
\hline Fatty acid & HH40CG60 & \multicolumn{1}{c}{ CG60 } & HH10CG50 & \multicolumn{1}{c}{ CG50 } \\
\hline C14:0 & $1.1 \pm 0.1$ & $0.9 \pm 0.1$ & $1.0 \pm 0.1$ & $1.2 \pm 0.0$ \\
C16:0 & $25.6 \pm 0.0$ & $22.2 \pm 0.1$ & $26.0 \pm 0.4$ & $28.0 \pm 0.6$ \\
C16:1 & $0.8 \pm 0.1$ & $0.9 \pm 0.1$ & $0.9 \pm 0.1$ & $0.8 \pm 0.0$ \\
C18:0 & $11.3 \pm 0.3$ & $12.6 \pm 0.1$ & $12.1 \pm 1.5$ & $12.2 \pm 0.0$ \\
C18:1 & $45.6 \pm 0.0$ & $46.0 \pm 0.1$ & $40.7 \pm 0.3$ & $39.6 \pm 0.5$ \\
C18:2 & $12.0 \pm 0.0$ & $12.1 \pm 0.1$ & $14.0 \pm 1.2$ & $13.8 \pm 0.0$ \\
C18:3 & $2.1 \pm 0.1$ & $3.2 \pm 0.1$ & $2.9 \pm 0.3$ & $2.5 \pm 0.0$ \\
C22:0 & N/D & $0.6 \pm 0.0$ & $0.5 \pm 0.0$ & N/D \\
C24:0 & $0.6 \pm 0.1$ & $1.4 \pm 0.1$ & $1.4 \pm 0.3$ & $0.8 \pm 0.0$ \\
\hline
\end{tabular}

of total identified fatty acids. The second major compound was palmitic acid (C16:0) with its highest proportion of $28.0 \%$. The third major fatty acid was linoleic acid (C18:2), the highest proportion of which was $16.3 \%$ of total identified fatty acids. The last major fatty acid was stearic acid (C18:0). Its highest proportion was $12.6 \%$ of total identified fatty acids. Proportions of the remaining fatty acids can be seen in Table 2 . The difference in proportion of the fatty acid concentration in samples that were taken from same cultures at $96 \mathrm{~h}$ and $144 \mathrm{~h}$ was not larger than four percent. The biggest changes were oleic acid for palmitic acid in HH10CG50 media and the opposite for CG50 after $48 \mathrm{~h}$. It should also be noted that behenic acid (C22:0) was above detectable levels only

Table 1 Endpoint lipid content, concentration, yield and specific lipid production in Rhodotorula toruloides CBS 14 and Rhodotorula glutinis CBS 3044 at the end of fermentation on different media

\begin{tabular}{|c|c|c|c|c|c|}
\hline Strain & Media carbon source & Cell lipid content (\%) & $\begin{array}{l}\text { Max. lipid } \\
\text { concentration (g/L) }\end{array}$ & $\begin{array}{l}\text { Lipid } \\
\text { yield } \\
\text { (g lipid/g carbon } \\
\text { source) }\end{array}$ & Final biomass ( $\mathrm{g} / \mathrm{L})$ \\
\hline \multirow[t]{9}{*}{ R. toruloides CBS 14} & $10 \% \mathrm{HH}$ & $46.8 \pm 1.0$ & $12.5 \pm 0.5$ & $0.25 \pm 0.02$ & $20.1 \pm 0.7$ \\
\hline & $55 \mathrm{~g} / \mathrm{LCG}$ & & & & \\
\hline & $55 \mathrm{~g} / \mathrm{LCG}$ & $46.2 \pm 5.6$ & $8.8 \pm 0.1$ & $0.20 \pm 0.01$ & $19.1 \pm 0.3$ \\
\hline & $10 \% \mathrm{HH}$ & $45.8 \pm 3.5$ & $6.5 \pm 0.5$ & $0.18 \pm 0.02$ & $13.5 \pm 0.01$ \\
\hline & $50 \mathrm{~g} / \mathrm{LCG}$ & & & & \\
\hline & $50 \mathrm{~g} / \mathrm{LCG}$ & $46.3 \pm 1.7$ & $6.3 \pm 0.2$ & $0.19 \pm 0.01$ & $13.5 \pm 0.01$ \\
\hline & $40 \% \mathrm{HH}$ & $54.6 \pm 1.5^{*}$ & $10.6 \pm 0.3^{*}$ & $0.23 \pm 0.01^{*}$ & $19.4 \pm 0.0^{*}$ \\
\hline & $60 \mathrm{~g} / \mathrm{l} \mathrm{CG}$ & & & & \\
\hline & $60 \mathrm{~g} / \mathrm{LCG}$ & $40.5 \pm 2.7^{*}$ & $5.7 \pm 0.4^{*}$ & $0.17 \pm 0.00^{*}$ & $28.0 \pm 0.5^{*}$ \\
\hline \multirow[t]{3}{*}{ R. glutinis CBS 3044} & $10 \% \mathrm{HH}$ & $36.4 \pm 0.6$ & $7.6 \pm 0.5$ & $0.15 \pm 0.01$ & $20.3 \pm 0.3$ \\
\hline & $55 \mathrm{~g} / \mathrm{L} \mathrm{CG}$ & & & & \\
\hline & $55 \mathrm{~g} / \mathrm{LCG}$ & $37.3 \pm 1.9$ & $7.1 \pm 0.1$ & $0.16 \pm 0.01$ & $21.1 \pm 0.01$ \\
\hline
\end{tabular}

Averages of triplicate cultivations with standard deviation, *average of duplicate cultivations with average deviation. lipid yield $=($ Total lipid concentration $) /($ Total carbon consumed) 
in cultivations using CG60 or HH10CG50, after $90 \mathrm{~h}$ cultivation.

\section{Discussion}

Crude glycerol proved to be a problematic substrate for oleaginous yeasts. Only one third of all tested strains showed substantial growth in plate-cultivation tests with CG as sole carbon source, all except one being basidiomycetes. All positively tested yeast strains were able to grow in medium containing up to $120 \mathrm{~g} / \mathrm{L}$ CG, although there were differences in growth rates between the strains. All strains showed comparatively good growth up to CG concentrations of $60 \mathrm{~g} / \mathrm{L}$, which is in accordance with results presented by Chatzifragou et al. [34].

Only one of the tested Lipomyces strains showed substantial growth on crude glycerol, but considerably slower than the tested red yeasts, in fact, its growth was already retarded at CG concentrations of $60 \mathrm{~g} / \mathrm{L}$. The reason for low tolerance of Lipomyces strains to crude glycerol in all cases is unknown as the literature clearly shows that they can utilise glycerol effectively [9]. Most likely some inhibitors from ash were the cause of low tolerance. Other inhibitors in trace amount like soaps, free fatty acids and residual catalysts might also be present in our samples due to differences in purification processes of each biodiesel production plant. Another observation was that mixing both CG and HH had a negative effect on both growth and assimilation of glycerol and xylose for $L$. starkeyi. The presence of xylose had a slightly negative effect on lipid accumulation in other oleaginous yeasts [35]. However, from the current data we cannot draw any valid conclusion about the physiological background of the different behaviour of the red yeasts and $L$. starkeyi in mixtures of CG and $\mathrm{HH}$.

In contrast, for the two in detail tested red yeast strains, we found a considerable activating effect of mixing $\mathrm{HH}$ with CG. Cells started consuming glycerol and producing lipids much earlier than in culture without $\mathrm{HH}$. At least for $R$. toruloides CBS 14 there was a clear effect on specific lipid production after the additional carbon sources were consumed. Thus, the higher glycerol conversion was not only due to an increased biomass because of the additional carbon sources but to an increased metabolic activity. The impact on specific lipid production was less pronounced in $R$. glutinis CBS 3044, still, the activating effect of adding $\mathrm{HH}$ was clearly visible for this strain as well.

From the results it can be concluded, that an addition of $\mathrm{HH}$ to the culture media has a positive effect on lipid production rate for Rhodotorula species. The addition of $\mathrm{HH}$ also had an improving effect on biomass production. An addition of just $10 \%$ of $\mathrm{HH}$ (approximately $2.6 \mathrm{~g} / \mathrm{L}$ xylose, $0.6 \mathrm{~g} / \mathrm{L}$ glucose, $0.8 \mathrm{~g} / \mathrm{L}$ acetic acid) resulted in consumption of all available carbon sources within $96 \mathrm{~h}$ of cultivation. Cultures without $\mathrm{HH}$ needed at least $24 \mathrm{~h}$ more to consume all glycerol in the media. The addition of $\mathrm{HH}$ did not impact specific glycerol uptake significantly but it accelerated reaching maximum lipid production rate in $R$. toruloides. This increased rate of lipid production by supplementing crude glycerol media with hemicellulose hydrolysate has not been reported before for yeast, and this is worth further investigations. In previous studies mixed substrates of lignocellulosic hydrolysates supplemented with glycerol have been performed. Shen et al. found a similar positive effect in Trichosporon fermentans of faster glycerol metabolism when adding sweet potato waste, which contained $30 \mathrm{~g} / \mathrm{L}$ of reducing sugars. Gong et al. described increased lipid yield and productivity in Cutaneotrichosporon curvatum (synonym Cryptococcus curvatus) when cultivating it in a mixture of corn stover hydrolysate and glycerol $[10,36]$. However, in another study with the oleaginous zygomycete Cunninghamella echinulata, where tomato hydrolysate was used with glycerol no such effect has been observed [37]. Our results showed higher total lipid concentrations when compared to recently published studies, which investigated mixtures with xylose and crude glycerol of higher quality (90-95\% vs our $80 \%$ ) as growth substrates [35]. This may be due to better controlled conditions in bioreactors compared to shake flask cultures.

The $40 \% \mathrm{HH}$ supplement to the culture media used to grow $R$. toruloides also resulted in the highest average lipid content. Even the 10\% HH supplement apparently decreased the time in which lipid contents of $>40 \%$ were achieved. Without $\mathrm{HH}$ addition, lipid content in CG media (CG50 and CG60) was similar to that in experiments with other $R$. toruloides strains grown using glycerol as carbon source [38]. It is possible that with proper adjustment of the ratio between $\mathrm{HH}$ and CG an even higher lipid concentrations could be achieved in less than $96 \mathrm{~h}$. Shortening the fermentation time has been described as a crucial aspect of an efficient process, as aerobic fermentations, in contrast to anaerobic processes, require substantial energy input for aeration [22]. The calculated yields of lipids per consumed substrate in $R$. toruloides in mixed media $(0.18-0.25)$ were higher or comparable to previously reported ones using glucose, which were $0.21 \mathrm{~g} / \mathrm{g}$ [39] or pure glycerol with $R$. toruloides $0.16 \mathrm{~g} / \mathrm{g}$ [35]. In C. curvatum in cornstover hydrolysate, lipid yield was $0.18 \mathrm{~g} / \mathrm{g}$ [36].

In our hands, it was necessary to add additional nitrogen to the hydrolysates when cultivating red yeasts, as the cells stopped growth and lipid accumulation during cultivation, probably due to too low nitrogen contents. For industrial processes, cheap and abundant nitrogen sources have to be identified. Food wastes are examples of 
such nitrogen sources, and recent results demonstrated that for instance waste milk or protein hydrolysates from chicken byproducts can be used for the production of yeast biomass [40, 41].

The activating effect by the addition of $\mathrm{HH}$ seems to be specific for red yeasts, as in L. starkeyi CBS 7786 the addition of $\mathrm{HH}$ had a rather inhibiting effect. The metabolism of xylose and glycerol are both generating glyceraldehyde-3-phosphate (G-3-P). In red yeasts, glycerol assimilation is possibly activated due to an increased amount of G-3-P. Glycerol is also required to form triacylglycerol (TAG), the major storage lipid in oleaginous yeasts. It is possible that the cell activates glycerol uptake to produce TAG from the additional carbon sources. Acetic acid could also play an important role in this process, as it is converted to acetyl-CoA, the precursor of fatty acid production [42]. Nevertheless, for the moment we can only speculate on the mechanism of the activation of the lipid metabolism by $\mathrm{HH}$ in Rhodotorula species. Further investigations are required to understand this phenomenon, for instance studies of the transcriptome of the yeasts.

The fatty acid profiles achieved for $R$. toruloides in this study are similar to those of vegetable oils like palm oil, and match biodiesel profile requirements [20, 43, 44]. Moreover, the yeast oil can also be used in other applications, such as for the replacement of vegetable oil in fish feed [24]. Interestingly, the fatty acid profile did not vary much despite that different cultivation media were used and the time of cultivations had varied.

\section{Conclusions}

This study proved that the low-value side products CG and hemicellulose can be used for production of lipids. Addition of HH to CG considerably increased lipid production rate in $R$. toruloides and to some extent in $R$. glutinis. Based on the results of our study it seems to be possible to add value to side streams of biodiesel production and pulp and paper industry. Glycerol utilisation and shorter cultivation times are crucial factors to improve the efficiency of biodiesel production based on oleaginous yeasts [22]. In addition, this study has proven that $R$. toruloides CBS 14 has a good potential for microbial lipid production utilising $\mathrm{CG}$ and $\mathrm{HH}$ as carbon sources during cultivation.

\section{Materials and methods} Yeast strains

Strains used are presented in Table 3.

All strains were stored at $-80{ }^{\circ} \mathrm{C}$ in $50 \% \mathrm{v} / \mathrm{v}$ glycerol and pre-grown on YPD plates (glucose $20 \mathrm{~g} / \mathrm{L}$ ( $\geq 99 \%$, Fluka Analytical, France), yeast extract $10 \mathrm{~g} / \mathrm{L}$ (Bacto ${ }^{\mathrm{TM}}$ Yeast Extract, BD, France), peptone 20 g/L (from casein,
Table 3 List of oleaginous yeast strains tested for the capability to utilise crude glycerol and hemicellulose hydrolysate as carbon source

\begin{tabular}{|c|c|}
\hline Species & Strain \\
\hline \multicolumn{2}{|l|}{ Lipomyces } \\
\hline lipofer & CBS 944 \\
\hline lipofer & CBS 5842 \\
\hline starkeyi & CBS 1807 \\
\hline starkeyi & CBS 2512 \\
\hline starkeyi & CBS 6047 \\
\hline starkeyi & CBS 7536 \\
\hline starkeyi & CBS 7544 \\
\hline starkeyi & CBS 7545 \\
\hline starkeyi & CBS 7786 \\
\hline starkeyi & CBS 7851 \\
\hline starkeyi & CBS 7852 \\
\hline \multicolumn{2}{|l|}{ Rhodotorula } \\
\hline babjevae & CBS 7808 \\
\hline babjevae & CBS 7809 \\
\hline glutinis & CBS 20 \\
\hline glutinis & CBS 2203 \\
\hline glutinis & CBS 2367 \\
\hline glutinis & CBS 2889 \\
\hline glutinis & CBS 2890 \\
\hline glutinis & CBS 3044 \\
\hline glutinis & CBS 5182 \\
\hline glutinis & CBS 5805 \\
\hline glutinis & CBS 7538 \\
\hline glutinis & CBS 9477 \\
\hline graminis & CBS 3043 \\
\hline minuta & CBS 8013 \\
\hline mucolaginosa & CFSQE 63 \\
\hline toruloides & CBS 14 \\
\hline
\end{tabular}

CBS-Westerdijk Fungal Biodiversity Institute, Utrecht, The Netherlands, CFSQE-The Center for Food Safety and Quality Enhancement, Griffin, Georgia, USA

Merck KGaA, Germany), agar powder 20 g/L (VWR chemicals, Belgium, $\mathrm{pH}=6$,) in $4{ }^{\circ} \mathrm{C}$ and were re-streaked every 4 weeks.

All cultivation media were sterilised by autoclaving for $20 \mathrm{~min}$ at $121^{\circ} \mathrm{C}$ and 4 bars unless stated otherwise. Fragile media components were sterile filtered using $0.2 \mu \mathrm{m}$ syringe filters (Sarstedt, Germany). Hemicellulose hydrolysate was filtered using $0.45 \mu \mathrm{m}$ bottle top unit filters followed by $0.2 \mu \mathrm{m}$ bottle top unit filters (VWR, Belgium).

To prepare a pre-culture, three types of media were used: (a) YPD-Glucose $20 \mathrm{~g} / \mathrm{L}$ ( $\geq 99 \%$, Fluka Analytical, France), Yeast extract $10 \mathrm{~g} / \mathrm{L}$ (Bacto ${ }^{\mathrm{TM}}$ Yeast Extract, BD, France), Peptone $20 \mathrm{~g} / \mathrm{L}$ (from casein, Merck 
KGaA, Germany), pH=6; (b) YPG-Glycerol $30 \mathrm{~g} / \mathrm{L}$, Yeast extract $10 \mathrm{~g} / \mathrm{L}$, Peptone $20 \mathrm{~g} / \mathrm{L}, \mathrm{pH}=6$; and (c) YPXG - Xylose $10 \mathrm{~g} / \mathrm{L}$, Glycerol $20 \mathrm{~g} / \mathrm{L}$, Yeast extract $10 \mathrm{~g} / \mathrm{L}$, Peptone $20 \mathrm{~g} / \mathrm{L}, \mathrm{pH}=6$.

All pre-cultures were started from yeast colonies grown on YPD plates and run in $500 \mathrm{~mL}$ baffled flasks in $100 \mathrm{~mL}$ of media, except the pre-cultures for the plate screening tests, which were done in $100 \mathrm{~mL}$ shake flasks with $10 \mathrm{~mL}$ of media. All starter cultures were incubated at $25^{\circ} \mathrm{C}$, for $72 \mathrm{~h}$.

For preparation of inoculum, cultures were collected into sterile $50 \mathrm{~mL}$ falcon tubes and centrifuged at $3000 \times g$ for $5 \mathrm{~min}$. The supernatant was discarded and the pellet washed with a solution of sterile filtered $\mathrm{NaCl}(9 \mathrm{~g} / \mathrm{L})$. This process was repeated once. After refilling with the $\mathrm{NaCl}$ solution, $\mathrm{OD}_{600}$ was measured to calculate inoculation volume to reach a starting $\mathrm{OD}_{600}$ of $\sim 1$.

Media used in growth tests contained- $1.7 \mathrm{~g} / \mathrm{L}$ Yeast Nitrogen Base (YNB) w/o amino acids and 2 g/L ammonium sulphate (DifcoTM, Becton-Dickinson and Company, USA), with different concentrations of crude glycerol, hemicellulose hydrolysate or combinations of both, together with $0.1 \mathrm{M}$ Potassium phosphate buffer pH 6. Tests were performed in $100 \mathrm{~mL}$ Erlenmeyer flasks, incubated at $25{ }^{\circ} \mathrm{C}$ on a rotary shaker at $120 \mathrm{rpm}$. In all shake flask tests, $\mathrm{OD}_{600}$ measurement was used to quantify cell growth. All media used are presented in Table 4.

$\mathrm{C} / \mathrm{N}$ ratios were determined as described in [36]. For yeast extract a $\mathrm{C} / \mathrm{N}$ ratio of $3.6: 1$ was assumed as described in [45], which also was confirmed by own analyses (unpublished results).

Hemicellulose hydrolysate was based on wheat-straw subjected to acid-based steam explosion which was processed by the Department of Biochemical Process
Engineering Luleå University of Technology, Sweden, as described previously [46]. According to HPLC-measurements, $\mathrm{HH}$ contained $26.2 \mathrm{~g} / \mathrm{L}$ xylose, $7 \mathrm{~g} / \mathrm{L}$ glucose, $6.6 \mathrm{~g} / \mathrm{L}$ acetic acid and trace amounts of arabinose $(<0.5 \mathrm{~g} / \mathrm{L})$. The $\mathrm{pH}$ of the $\mathrm{HH}$ was set to 6 by addition of $5 \mathrm{M} \mathrm{NaOH}$. In the experiments, the $\mathrm{HH}$ was diluted with water.

Crude glycerol was provided by Perstorp Holding AB. The composition was $80 \%$ glycerol, $5 \%$ ash, $15 \%$ water, $0.5 \%$ methanol and trace amounts of feedstock-vegetable oil.

\section{Growth experiments \\ Crude glycerol and hemicellulose growth test}

To test strains for the ability to grow on CG, plates with YNB and agar $(16 \mathrm{~g} / \mathrm{L})$ were used without carbon source. The inoculation cultures were diluted to reach a density of $\sim 0.5 \mathrm{McF}$ arland and plated on the testing plates. Testing plates were (I) a CG drop was placed in the centre of the plate, (II) a sterile disk soaked in 50\% CG was placed in the centre of the plate and (III) negative control without any carbon source. All the plates were incubated for $72 \mathrm{~h}$ in $25^{\circ} \mathrm{C}$.

For confirming the growth on mixed $\mathrm{CG}$ and $\mathrm{HH}$, six liquid media were used: Control, sCG3, sCG6, sCG9, sCG12 and sHemi (Table 4). $20 \mathrm{ml}$ of media was used in $100 \mathrm{ml}$ Erlenmeyer flasks. Cultures were grown for $96 \mathrm{~h}$ at $25^{\circ} \mathrm{C}$ on a rotary shaker at $120 \mathrm{rpm}$, with $\mathrm{OD}_{600}$ measurements after $72 \mathrm{~h}$ and $96 \mathrm{~h}$.

A mixture of CG and $\mathrm{HH}$ (sHH40CG60, C/N ratio 78) was compared to $\mathrm{CG}$ alone (sCG60, $\mathrm{C} / \mathrm{N}$ ratio $\sim 58$ ) or a control (Table 4). All samples were set up in duplicates. Cultures were grown for $72 \mathrm{~h}$ with $\mathrm{OD}_{600}$ measurements each $24 \mathrm{~h}$ and subsequently every $6 \mathrm{~h}$.

Table 4 Media used in this study; $\mathrm{HH}$ —-hemicellulose hydrolysate, CG—Crude glycerol, s—shake flask culture

\begin{tabular}{|c|c|c|}
\hline Name & Media components & \\
\hline Control & $\begin{array}{l}20 \mathrm{~g} / \mathrm{L} \text { glucose, YNB } 1.7 \mathrm{~g} / \mathrm{L}, 2 \mathrm{~g} / \mathrm{L} \mathrm{NH}_{4} \mathrm{SO}_{4}, 0.1 \mathrm{M} \text { Potassium } \\
\text { phosphate buffer pH 6, YE } 0.75 \mathrm{~g} / \mathrm{L}\end{array}$ & \\
\hline sHemi & $40 \% \mathrm{HH}$ & +YNB $1.7 \mathrm{~g} / \mathrm{L}, 2 \mathrm{~g} / \mathrm{L} \mathrm{NH}_{4} \mathrm{SO}_{4}, 0.1 \mathrm{M}$ Potassium phos- \\
\hline sCG30 & $30 \mathrm{~g} / \mathrm{L} \mathrm{CG}$ & phate buffer pH 6, YE 0.75 g/L \\
\hline sCG60 & $60 \mathrm{~g} / \mathrm{L} \mathrm{CG}$ & \\
\hline sCG90 & $90 \mathrm{~g} / \mathrm{L} \mathrm{CG}$ & \\
\hline sCG120 & $120 \mathrm{~g} / \mathrm{L} \mathrm{CG}$ & \\
\hline sHH40CG60 & $40 \% \mathrm{HH}+60 \mathrm{~g} / \mathrm{L} \mathrm{CG}$ & \\
\hline HH40CG60 & $40 \% \mathrm{HH}+60 \mathrm{~g} / \mathrm{L} \mathrm{CG}$ & $+Y N B 1.7 \mathrm{~g} / \mathrm{L}, 2 \mathrm{~g} / \mathrm{L} \mathrm{NH}_{4} \mathrm{SO}_{4}, \mathrm{YE} 0.75 \mathrm{~g} / \mathrm{L}, 1 \mathrm{~g} / \mathrm{L} \mathrm{MgCl}_{2}$ \\
\hline HH10CG50 & $10 \% \mathrm{HH}+60 \mathrm{~g} / \mathrm{LCG}$ & \\
\hline CG50 & $50 \mathrm{~g} / \mathrm{L} \mathrm{CG}$ & \\
\hline CG60 & $60 \mathrm{~g} / \mathrm{L} \mathrm{CG}$ & \\
\hline HH10CG55 & $10 \% \mathrm{HH}+55 \mathrm{~g} / \mathrm{L} \mathrm{CG}$ & \\
\hline CG55 & $55 \mathrm{~g} / \mathrm{L} \mathrm{CG}$ & \\
\hline
\end{tabular}




\section{Bioreactor cultivations}

Fermentations were performed in $500 \mathrm{~mL}$ bioreactors Multifors 2 (Infors HT, Switzerland) containing $350 \mathrm{ml}$ medium. The fermentation conditions were $25^{\circ} \mathrm{C}, \mathrm{pH}=6$ (acid $3 \mathrm{M} \mathrm{H}_{3} \mathrm{PO}_{4}$, base $5 \mathrm{M} \mathrm{NaOH}$ ), stirrer starting at $200 \mathrm{rpm}$ with maximum speed $800 \mathrm{rpm}$, aeration $0.3 \mathrm{~L} /$ min $(0.9 \mathrm{vvm})$ and DOT set to $20 \%$. Polypropylene glycol 2000 was added as antifoaming agent, when needed. Unless stated otherwise, each tested strain was cultivated in triplicate. The media tested are stated in Table 4. Fermentations were performed for 120 or $144 \mathrm{~h}$ depending on strain and carbon consumption. Biomass concentrations were determined by cell dry weight determination.

Specific lipid production was calculated for the midpoint of an according measuring interval:

\section{Specific lipid production$$
=(\Delta \text { Lipid concentration }) /(\text { Average } X * \Delta t)
$$

$\Delta$ Lipids were determined as difference between the measured lipid concentration values after the respective midpoints and before. Average X were calculated from the mean of biomasses determined after and before the respective midpoints. $\Delta t$ was the time interval between the two measuring points.

\section{Analytical methods}

The optical density $\left(\mathrm{OD}_{600}\right)$ was measured at a wavelength of $\lambda=600 \mathrm{~nm}$ using CO8000 Cell density meter (Nordic Biolabs). HPLC and cell dry weight measurements were performed as described before [19]. To prepare samples for lipid extraction, harvested cells were freeze dried in vacuum for $72 \mathrm{~h}$ with condenser set to - $100{ }^{\circ} \mathrm{C}$ (CoolSafe Scanvac, LaboGene ApS, Denmark). Lipid concentration and fatty acid profile were determined as described earlier [19]. For rapid determination of lipid content we used our recently described FT-NIR method [33].

\section{Abbreviations}

CG: Crude Glycerol; FAME: Fatty Acid Methyl Esters; FT-NIR: Fourier Transform Near-Infra-red; HH: Hemicellulose Hydrolysate; YNB: Yeast Nitrogen Base; YM: Yeast Extract-Malt Extract; YPD: Yeast Peptone Dextrose; HIP: Hexane: Isopropanol.

\section{Supplementary Information}

The online version contains supplementary material available at https://doi. org/10.1186/s13068-021-01916-y.

Additional file 1. Figure 1. Specific lipid production rates of $R$. toruloides CBS 14 and R. glutinis CBS 3044 in 55 g/L crude glycerol media and 55 g/L crude glycerol media with $10 \%$ hemicellulose hydrolysate. Negative values are due to a decrase of lipid concentrations during the measuring interval.
Additional file 2. Figure 2. R. toruloides CBS 14, HH40CG60 media grown in duplicates, dry weight and change of compounds concentration in media over time, average lipid concentration was $10.57 \mathrm{~g} / \mathrm{L}$ after $70 \mathrm{~h}$. Glucose, xylose and acetic acid are presented on secondary y axis.

Additional file 3. Figure 3. Bioreactor cultivation of $R$. toruloides CBS 14 in triplicates, (A) CG50 medium, (B) HH10CG50 medium. Glucose, xylose and acetic acid are presented on secondary $Y$ axis.

\section{Acknowledgements}

Not applicable.

\section{Authors' contributions}

MC was involved in designing the study, performed the major part of the lab work, and wrote the first draft of the manuscript. SaS was involved in laboratory work, evaluation of the results and performed a major contribution to writing. JB contributed to laboratory work, evaluation of the results and perfromed a major contribution to writing. MS and VP provided a major contribution to designing the study, to evaluate the results and to write the manuscript. All authors read and approved the final manuscript. All authors read and approved the final manuscript.

\section{Funding}

Open access funding provided by Swedish University of Agricultural Sciences. The research was supported by The Swedish Research Council for Environment, Agricultural Sciences and Spatial Planning (Formas), grant numbers 213-2013-80 and 2018-01877.

\section{Availability of data and materials}

The datasets used and/or analysed during the current study are available from the corresponding author on reasonable request.

\section{Declarations}

Ethics approval and consent to participate Not applicable.

\section{Consent for publication.}

All authors agreed to publish this article.

\section{Competing interests}

The authors declare that they have no competing interests.

Received: 2 December 2020 Accepted: 23 February 2021

Published online: 12 March 2021

\section{References}

1. Papanikolaou S, Aggelis G: Microbial products from wastes and residues. FEMS Microbiol Lett 2020, 367(19).

2. Knothe G. Biodiesel and renewable diesel: a comparison. Prog Energy Combust Sci. 2010;36(3):364-73.

3. Okoye PU, Hameed BH. Review on recent progress in catalytic carboxylation and acetylation of glycerol as a byproduct of biodiesel production. Renew Sustain Energy Rev. 2016:53:558-74.

4. Abbas J, Hussain S, lqbal MJ, Nadeem H, Qasim M, Hina S, Hafeez F. Oil industry waste: a potential feedstock for biodiesel production. Environ Technol. 2016;37(16):2082-7.

5. Li X, Chen G, Liu C, Ma W, Yan B, Zhang J. Hydrodeoxygenation of ligninderived bio-oil using molecular sieves supported metal catalysts: A critical review. Renew Sustain Energy Rev. 2017;71:296-308.

6. Poladyan A, Blbulyan S, Semashko T, Dziameshka V, Zhukouskaya L, Trchounian A: Application of organic waste glycerol to produce crude extracts of bacterial cells and microbial hydrogenase-the anode enzymes of bio-electrochemical systems. FEMS Microbiol Lett 2020;367(7). 
7. Gajdos P, Hambalko J, Slany O, Certik M: Conversion of waste materials into very long chain fatty acids by the recombinant yeast Yarrowia lipolytica. FEMS Microbiol Lett 2020, 367(6).

8. Xin B, Wang Y, Tao F, Li L, Ma C, Xu P. Co-utilization of glycerol and lignocellulosic hydrolysates enhances anaerobic 1,3-propanediol production by Clostridium diolis. Sci Rep. 2016;6:19044.

9. Spier F, Buffon JG, Burkert CA. Bioconversion of raw glycerol generated from the synthesis of biodiesel by different oleaginous yeasts: lipid content and fatty acid profile of biomass. Indian J Microbiol. 2015;55(4):415-22.

10. Shen $Q$, Lin H, Zhan J, Wang Q, Zhao Y. Sweetpotato vines hydrolysate induces glycerol to be an effective substrate for lipid production of Trichosporon fermentans. Bioresour Technol. 2013;136:725-9.

11. Yen $\mathrm{H}-\mathrm{W}$, Yang $\mathrm{Y}-\mathrm{C}, \mathrm{Yu} \mathrm{Y}-\mathrm{H}$. Using crude glycerol and thin stillage for the production of microbial lipids through the cultivation of Rhodotorula glutinis. J Biosci Bioeng. 2012;114(4):453-6.

12. Saenge C, Cheirsilp B, Suksaroge TT, Bourtoom T. Potential use of oleaginous red yeast Rhodotorula glutinis for the bioconversion of crude glycerol from biodiesel plant to lipids and carotenoids. Process Biochem. 2011;46(1):210-8.

13. Diaz-Fernandez D, Aguiar TQ, Martin VI, Romani A, Silva R, Domingues $L$, Revuelta JL, Jimenez A. Microbial lipids from industrial wastes using xylose-utilizing Ashbya gossypii strains. Bioresour Technol. 2019;293:122054.

14. Biely P, Singh S, Puchart V: Towards enzymatic breakdown of complex plant xylan structures: State of the art. Biotechnology Advances 2016, 34.

15. Isikgor $\mathrm{FH}$, Becer CR. Lignocellulosic biomass: a sustainable platform for the production of bio-based chemicals and polymers. Polymer Chemistry. 2015;6(25):4497-559.

16. Gírio F, Fonseca C, Carvalheiro F, Duarte L, Marques S, Lukasik R. HemicelIuloses for Fuel Ethanol: A Review. Biores Technol. 2010;101:4775-800.

17. Jönsson $L$, Martin C. Pretreatment of lignocellulose: Formation of inhibitory by-products and strategies for minimizing their effects. Bioresour Technol. 2016;199:103-12.

18. Brandenburg J, Poppele I, Blomqvist J, Puke M, Pickova J, Sandgren M, Rapoport A, Vedernikovs N, Passoth V. Bioethanol and lipid production from the enzymatic hydrolysate of wheat straw after furfural extraction. Appl Microbiol Biotechnol. 2018;102(14):6269-77.

19. Brandenburg J, Blomqvist J, Pickova J, Bonturi N, Sandgren M, Passoth V. Lipid production from hemicellulose with Lipomyces starkeyi in a pH regulated fed-batch cultivation. Yeast. 2016;33(8):451-62.

20. Dubois V, Breton $S$, Linder M, Fanni J, Parmentier M. Fatty acid profiles of 80 vegetable oils with regard to their nutritional potential. Eur J Lipid Sci Technol. 2007;109(7):710-32.

21. Schmidt JH. Life cycle assessment of five vegetable oils. J Clean Prod. 2015;87:130-8.

22. Karlsson H, Ahlgren S, Sandgren M, Passoth V, Wallberg O, Hansson PA. A systems analysis of biodiesel production from wheat straw using oleaginous yeast: process design, mass and energy balances. Biotechnol Biofuels. 2016;9:229.

23. Karlsson H, Ahlgren S, Sandgren M, Passoth V, Wallberg O, Hansson PA. Greenhouse gas performance of biochemical biodiesel production from straw: soil organic carbon changes and time-dependent climate impact. Biotechnol Biofuels. 2017;10:217.

24. Blomqvist J, Pickova J, Tilami SK, Sampels S, Mikkelsen N, Brandenburg J, Sandgren M, Passoth V. Oleaginous yeast as a component in fish feed. Sci Rep. 2018;8(1):15945.

25. Biddy MJ, Davis R, Humbird D, Tao L, Dowe N, Guarnieri MT, Linger JG, Karp EM, Salvachúa D, Vardon DR, et al. The Techno-Economic Basis for Coproduct Manufacturing To Enable Hydrocarbon Fuel Production from Lignocellulosic Biomass. ACS Sustainable Chemistry \& Engineering. 2016;4(6):3196-211.

26. Sitepu EK, Heimann K, Raston CL, Zhang W: Critical evaluation of process parameters for direct biodiesel production from diverse feedstock. Renewable and Sustainable Energy Reviews 2020, 123.

27. Valdés G, Mendonça RT, Parra C, Aggelis G. Patterns of lignocellulosic sugar assimilation and lipid production by newly isolated yeast strains from chilean valdivian forest. Appl Biochem Biotechnol. 2020;192(4):1124-46.
28. Passoth V, Sandgren M. Biofuel production from straw hydrolysates: current achievements and perspectives. Appl Microbiol Biotechnol. 2019;103(13):5105-16.

29. Boguslawska-Was E, Dlubala A, Laskowska M. The role of Rhodotorula mucilaginosa in selected biological process of wild fish. Fish Physiol Biochem. 2019;45(2):511-21.

30. Tulloch AP, Spencer JFT. Extracellular glycolipids of rhodotorula species: the isolation and synthesis of 3-D-Hydroxypalmitic and 3-D-Hydroxystearic Acids. Can J Chem. 1964;42(4):830-5.

31. Cho DH, Chae HJ, Kim EY. Synthesis and characterization of a novel extracellular polysaccharide by Rhodotorula glutinis. Appl Biochem Biotechnol. 2001;95(3):183-94.

32. Lopes HJS, Bonturi N, Kerkhoven EJ, Miranda EA, Lahtvee PJ. C/N ratio and carbon source-dependent lipid production profiling in Rhodotorula toruloides. Appl Microbiol Biotechnol. 2020;104(6):2639-49.

33. Chmielarz M, Sampels S, Blomqvist J, Brandenburg J, Wende F, Sandgren M, Passoth V. FT-NIR: a tool for rapid intracellular lipid quantification in oleaginous yeasts. Biotechnol Biofuels. 2019;12:169.

34. Chatzifragkou A, Makri A, Belka A, Bellou S, Mavrou M, Mastoridou M, Mystrioti P, Onjaro G, Aggelis G, Papanikolaou S. Biotechnological conversions of biodiesel derived waste glycerol by yeast and fungal species. Energy. 2011;36(2):1097-108.

35. Diamantopoulou P, Filippousi R, Antoniou D, Varfi E, Xenopoulos E, Sarris D, Papanikolaou S: Production of added-value microbial metabolites during growth of yeast strains on media composed of biodiesel-derived crude glycerol and glycerol/xylose blends. FEMS Microbiol Lett 2020, $367(10)$.

36. Gong Z, Zhou W, Shen H, Zhao ZK, Yang Z, Yan J, Zhao M. Co-utilization of corn stover hydrolysates and biodiesel-derived glycerol by Cryptococcus curvatus for lipid production. Bioresour Technol. 2016;219:552-8.

37. Fakas S, Papanikolaou S, Galiotou-Panayotou M, Komaitis M, Aggelis G. Organic nitrogen of tomato waste hydrolysate enhances glucose uptake and lipid accumulation in Cunninghamella echinulata. J Appl Microbiol. 2008;105(4):1062-70.

38. Gao Z, Ma Y, Wang Q, Zhang M, Wang J, Liu Y. Effect of crude glycerol impurities on lipid preparation by Rhodosporidium toruloides yeast 32489 . Biores Technol. 2016;218:373-9.

39. Wiebe MG, Koivuranta K, Penttila M, Ruohonen L. Lipid production in batch and fed-batch cultures of Rhodosporidium toruloides from 5 and 6 carbon carbohydrates. BMC Biotechnol. 2012;12:26.

40. Myint KT, Otsuka M, Okubo A, Mitsuhashi R, Oguro A, Maeda H, Shigeno T, Sato K, Nakajima-Kambe T: Isolation and identification of flower yeasts for the development of mixed culture to produce single-cell protein from waste milk. Bioresource Technology Reports 2020, 10.

41. Lapena D, Kosa G, Hansen LD, Mydland LT, Passoth V, Horn SJ, Eijsink VGH. Production and characterization of yeasts grown on media composed of spruce-derived sugars and protein hydrolysates from chicken by-products. Microb Cell Fact. 2020;19(1):19.

42. Passoth V. Lipids of Yeasts and Filamentous Fungi and Their Importance for Biotechnology. In: Sibirny AA, editor. Biotechnology of Yeasts and Filamentous Fungi. Cham: Springer International Publishing; 2017. p. 149-204.

43. Kot AM, Błażejak S, Kurcz A, Gientka I, Kieliszek M. Rhodotorula glutinispotential source of lipids, carotenoids, and enzymes for use in industries. Appl Microbiol Biotechnol. 2016;100:6103-17.

44. Liang Y, Cui Y, Trushenski J, Blackburn JW. Converting crude glycerol derived from yellow grease to lipids through yeast fermentation. Bioresour Technol. 2010;101(19):7581-6.

45. Mustafa U. Kaur G: Effects of carbon and nitrogen sources and ratio on the germination, growth and sporulation characteristics of Metarhizium anisopliae and Beauveria bassiana isolates. Afr J Agric Res. 2009;3:922-30.

46. Helmerius J, von Walter JV, Rova U, Berglund KA, Hodge DB. Impact of hemicellulose pre-extraction for bioconversion on birch Kraft pulp properties. Bioresour Technol. 2010;101(15):5996-6005.

\section{Publisher's Note}

Springer Nature remains neutral with regard to jurisdictional claims in published maps and institutional affiliations. 